\title{
Startup Speed with Dead Band in Wind Farms with Low-Medium Wind Speed Profile-Case Study of Hong Kong
}

\author{
Zuliang Yin, Bo Bai, Jiani Liu, Sheng Su \\ College of Electrical and Electronic Engineering, Changsha University of Science and Technology, Changsha, China \\ Email: yinzuliang0614@163.com, eessheng@163.com
}

How to cite this paper: Yin, Z.L., Bai, B., Liu, J.N. and Su, S. (2017) Startup Speed with Dead Band in Wind Farms with Low-Medium Wind Speed Profile-Case Study of Hong Kong. Energy and Power Engineering, 9, 562-572.

https://doi.org/10.4236/epe.2017.94B062

Received: March 6, 2017

Accepted: March 30, 2017

Published: April 6, 2017

\begin{abstract}
Wind turbines are usually designed and operated with fixed startup speed. It could perform startup and shutdown operations repeatedly when the wind fluctuates around the startup speed. The excessive stress induced by frequent startup and shutdown could enhance the likelihood of component failure and hence negatively impact the availability of a wind turbine. Startup speed with dead band is proposed in this article to prevent the wind turbine from frequent startup. 22 years wind data from the Cheung Chau wind station in Hong Kong are analyzed to evaluate the reduction in the number of startup and potential loss of wind power production using the proposed approach. Numerical simulation suggests that the number of startup could be reduced by half with trivial reduction in potential wind power generation in most of investigated sites once an appropriate dead band is adopted.
\end{abstract}

\section{Keywords}

Wind Power, Wind Turbine, Startup, Dead Band

\section{Introduction}

Wind turbine is a unique power generating system since its components are subject to highly irregular loading under turbulent wind conditions [1]. They are exposed to the risk of component failure due to the difference between the extreme and the average wind regimes [2]. The component failure could cause not only maintenance cost but also reduction in generated electricity. It is speculated that the maintenance cost may account for $10 \%$ to $30 \%$ of the total income of wind turbines [1].

Wind turbines operate in the presence of large uncertainties. Many outliers are likely to be generated, particularly during transient operations such as star- 
tup and shutdown [3]. Wind turbines are designed and operated with a given startup speed. Therefore, it could perform shutdown and startup operations repeatedly when the wind speed fluctuates around its startup speed.

The excessive stress and operation induced by frequent startup/shutdown could enhance the likelihood of component failure of a wind turbine. On one hand, large number of startup/shutdown could accelerate the aging and fatigue of mechanical components. On the other hand, frequent operation of circuit breaker or switchgear during off-grid and grid connection operation could result in notable rise in temperature, and consequently, lead to malfunction of circuit breaker or switchgear.

Wind farms are usually installed in countries with high wind speeds. As more wind farms are installed each year, sites with high quality wind resources are becoming scarcer. Low and medium wind speed sites are more common than high wind speed sites. There are opportunities for wind farms to be located closer to existing power grid and load center with low and medium wind speed [4]. Since wind could fluctuate around startup speed of wind turbines with higher likelihood in these stations than the sites with high wind speed, it is speculated that wind farms with low wind condition could suffer more difficulty in frequent startup and shutdown of wind turbines.

Deadband, an interval of no action occurs, is widely used in automatic control applications to prevent oscillation or repeated activation-deactivation cycles [5] [6]. Startup speed with a dead band could be utilized to prevent frequent startup/shutdown of wind turbines. Since wind power is proportional to the cube of wind speed, the slight reduction in wind power generation caused by the dead band could be compensated by the potential benefit arise from the reduction in the number of startup operations that reduces component failure and enhances availability.

Wind data from the Cheung Chau meteorological station in Hong Kong (HK) is analyzed in this paper to investigate the effect of dead band in wind turbine operations. The paper is organized as follows. The existing and potential wind farms in $\mathrm{HK}$ and the wind data utilized for numerical simulation are analyzed in Section 2. The feasibility of startup speed with dead band is analyzed in Section 3. Numerical simulation is given in Section 4 to evaluate performance of startup speed with dead band. Section 5 concludes the article.

\section{Potential Wind Farm and Wind Data}

\subsection{Wind Farms in HK}

HK consumed 48,806 GWh electricity in 2012 [7]. In order to support the Government's sustainable development policy which promotes the development of renewable energy, HK Electric has been embarking on developing wind farms [8]. The Lamma Winds, established in 23 Feb. 2006, is the first wind power station in HK. As a pilot wind project, there is only a single Nordex N50/800 wind turbine perched atop Tai Ling on the northern part of Lamma Island as shown in Figure 1. The average wind speed is $5.5 \mathrm{~m} / \mathrm{s}$. 


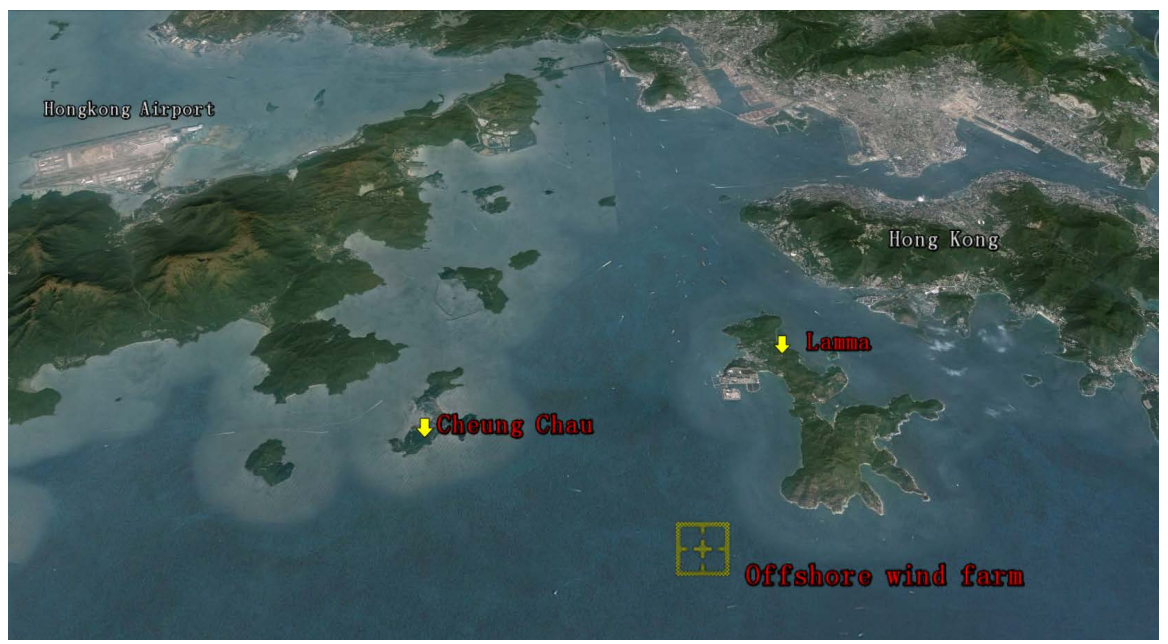

Figure 1. Geographical location of investigated sites.

Based on experience gained from the operation of Lamma Winds, HK Electric is proposing to build an offshore wind farm in HK near Lamma Island [9]. The proposed wind farm will be located at a 600 -hectare site about $3.5 \mathrm{~km}$ southwest of Lamma Island as shown in Figure 1. The planned capacity of the offshore wind farm is about $100 \mathrm{MW}$ comprising 28 to 35 sets of 2.3 to $3.6 \mathrm{MW}$ class wind turbines which will be linked up by cables to an offshore or onshore substation where the output voltage will be stepped up for connecting to HK switching station in Lamma Power Station.

\subsection{Wind Data}

The wind data of Lamma Winds and that of potential wind farm are not available via public service. The weather observation data of Cheung Chau meteorological station [10], which located at the southern part of Cheung Chau, is utilized in this article. The station has very good exposure in all directions as it is situated in an outlying island free from the impact of high mountains or high-rise buildings in its vicinity. Its annual wind data is representative of the prevailing wind in HK throughout the year. Moreover, the Cheung Chau station is about $10 \mathrm{~km}$ away from Lamma wind farm and potential offshore wind farm. Therefore, it is appropriate to analyze startup/shutdown of wind turbines in HK with observed wind data in Cheung Chau station.

The geographical locations of these sites are listed in Table 1. All sites locate in the south coastal areas of HK are facing the open sea. Cheung Chau meteorological station measures variables such as air temperature, relative humidity and wind speed, among others, with a sample frequency of 10 minutes. It was automated in 1992. In this paper, 1,110,286 observed 10-minute wind data of 22 years (from May. 30, 1992 to Dec. 31, 2013) are analyzed. The mean wind speed of Cheung Chau is $5.10 \mathrm{~m} / \mathrm{s}$. The monthly mean wind speed is calculated and plotted as shown in Figure 2 .

It can be observed that there is a notable diurnal variation in wind speed. The HK wind regime is characterized by the strong North monsoon wind in the 
Table 1. Geographical information of wind farm \& Meteorological station.

\begin{tabular}{|c|c|c|c|}
\hline Site & Longtitude & Latitude & Elevation \\
\hline Lamma wind farm & $\mathrm{E} 114^{\circ} 07^{\prime} 15^{\prime \prime}$ & $\mathrm{N} 22^{\circ} 13^{\prime} 72^{\prime \prime}$ & $83 \mathrm{~m}$ \\
\hline potential offshore wind farm & $\mathrm{E} 114^{\circ} 05^{\prime} 12^{\prime \prime}$ & $\mathrm{N} 22^{\circ} 10^{\prime} 26^{\prime \prime}$ & $0 \mathrm{~m}$ \\
\hline Cheung Chau station & $\mathrm{E} 114^{\circ} 01^{\prime} 35^{\prime \prime}$ & $\mathrm{N} 22^{\circ} 12^{\prime} 04^{\prime \prime}$ & $57 \mathrm{~m}$ \\
\hline
\end{tabular}

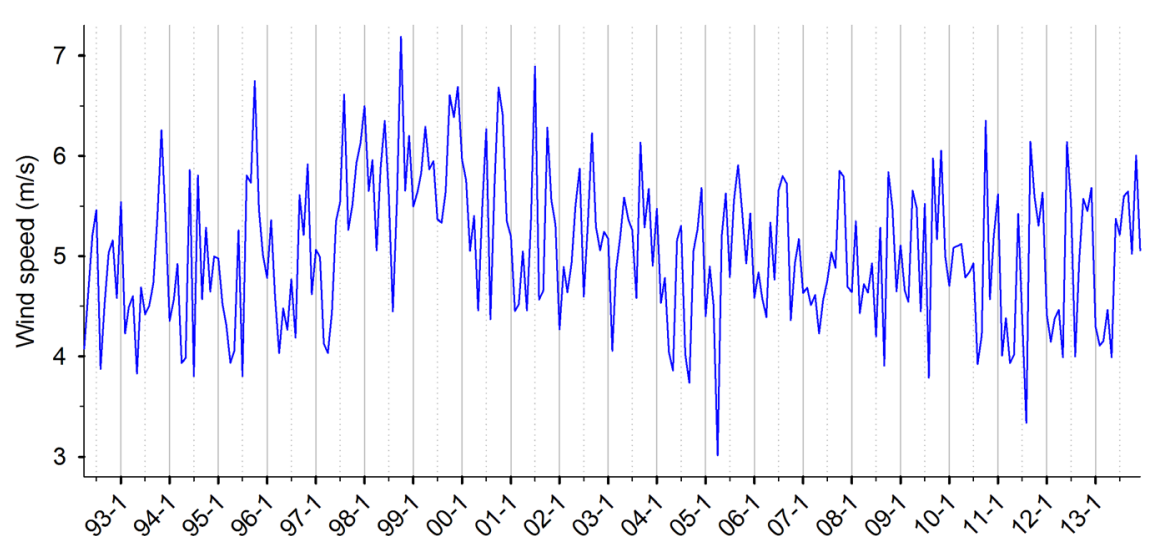

Figure 2. Monthly mean wind speed.

winter and tropical cyclone in the summer. It seems that the spring from March to June is characterized with low wind while the remaining time of a year is usually characterized by higher wind speed.

Since wind turbines perform startup/shutdown frequently under the low wind regime and wind fluctuates around the startup speed, there could be more startup in the days with lower wind speed than the days with higher wind speed. In order to find out whether this is true, the data are analyzed as follows.

- The number of wind speed over and lower than the startup speed is counted as number of startup/shutdown of wind turbine due to fluctuation of wind speed. Altogether, there are 31,213 startups due to fluctuation in wind speed throughout the investigated time span. Therefore, a wind turbine could startup 4 times a day on average. That is notable burden to the fatigue of a wind turbine.

- The mean wind speed and the number of startup in each month are calculated. Thereafter, they are collated in monthly mean wind speed in ascending order and plotted as shown in Figure 3. The months with highest and lowest wind speed are listed in Table 2.

It can be observed from Figure 3 and Table 2 that:

- The number of startup varies indistinctively from month to month. The number of monthly startup ranges from 43 to 235 and the mean wind speed ranges from $3.016 \mathrm{~m} / \mathrm{s}$ to $7.187 \mathrm{~m} / \mathrm{s}$.

- There are notable opposite tendency in the two curves. The number of startup declines gradually with higher wind speed. The correlation coefficient of the two curves is -0.7897 , which indicates there are strong negative correlation between the wind speed and the number of startup. 


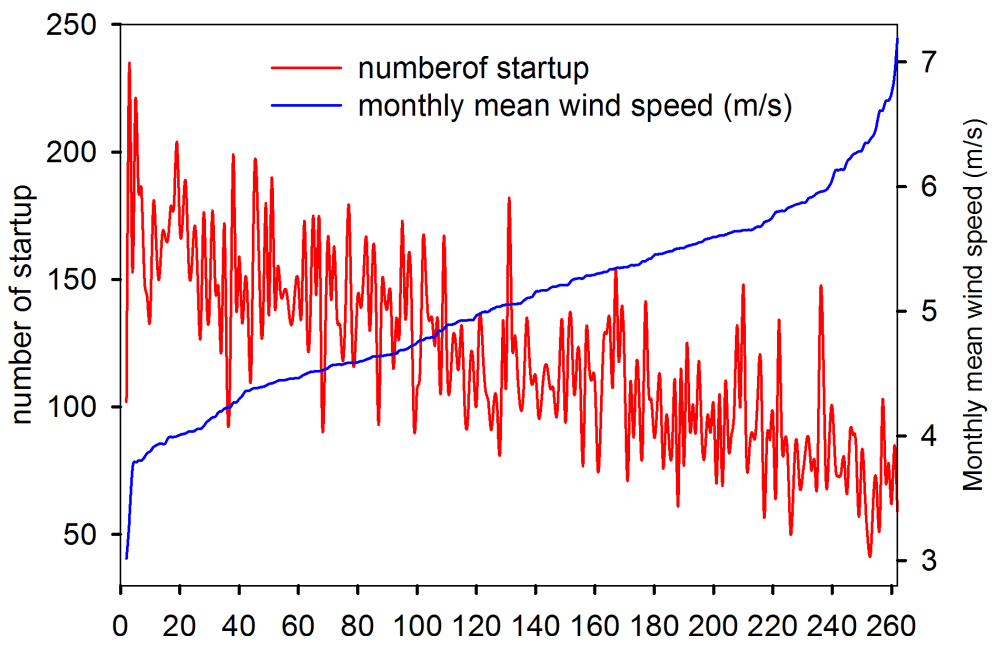

Figure 3. Monthly mean wind speed vs. number of startup.

Table 2. Information of the months with highest and lowest wind.

\begin{tabular}{cccccc}
\hline month & mean wind & Startup & month & mean wind & startup \\
\hline Oct. 1998 & $7.187 \mathrm{~m} / \mathrm{s}$ & 59 & Apr. 2005 & $3.016 \mathrm{~m} / \mathrm{s}$ & 102 \\
Jul. 2001 & $6.893 \mathrm{~m} / \mathrm{s}$ & 85 & Aug. 2011 & $3.337 \mathrm{~m} / \mathrm{s}$ & 235 \\
Oct. 1995 & $6.748 \mathrm{~m} / \mathrm{s}$ & 62 & Sept. 2004 & $3.736 \mathrm{~m} / \mathrm{s}$ & 153 \\
Dec. 1999 & $6.689 \mathrm{~m} / \mathrm{s}$ & 78 & Aug. 2009 & $3.788 \mathrm{~m} / \mathrm{s}$ & 220 \\
Oct. 2000 & $6.683 \mathrm{~m} / \mathrm{s}$ & 71 & Jul. 1995 & $3.803 \mathrm{~m} / \mathrm{s}$ & 186 \\
Aug. 1997 & $6.611 \mathrm{~m} / \mathrm{s}$ & 103 & May 1993 & $3.828 \mathrm{~m} / \mathrm{s}$ & 151 \\
\hline
\end{tabular}

Majority of the months with both highest and lowest wind speed occurs in the summer. It seems the months with highest wind are caused by durable and strong tropical cyclone while the months with lowest wind are caused by absence of tropical cyclone.

\section{Feasibility of Startup Speed with Dead Band}

The use of dead band has gotten extensive application in control engineering [5] [6]. Usually, the purpose is to prevent oscillation or repeated activation-deactivation cycles and avoids unnecessary control. Undoubtedly, the use of dead band could prevent unnecessary startup/shutdown of wind turbine. However, the reduction in the number of startup/shutdown is achieved at the cost of reduction in wind power production, which should be evaluated as well. The wind turbine used in Lamma Winds, Nordex N50/800 turbine [11] with a startup speed of 3.0 $\mathrm{m} / \mathrm{s}$, is utilized in this study. The wind power curve is plotted as shown in Figure 4.

Since wind power that can be exploited is proportional to the cube of wind speed, the power production is rather low when the speed is below $5.0 \mathrm{~m} / \mathrm{s}$ as shown the wind power curve. Therefore, it seems reasonable to establish a dead band below $5.0 \mathrm{~m} / \mathrm{s}$ to avoid unnecessary startup/shutdown at the cost of slight reduction in wind power production. 


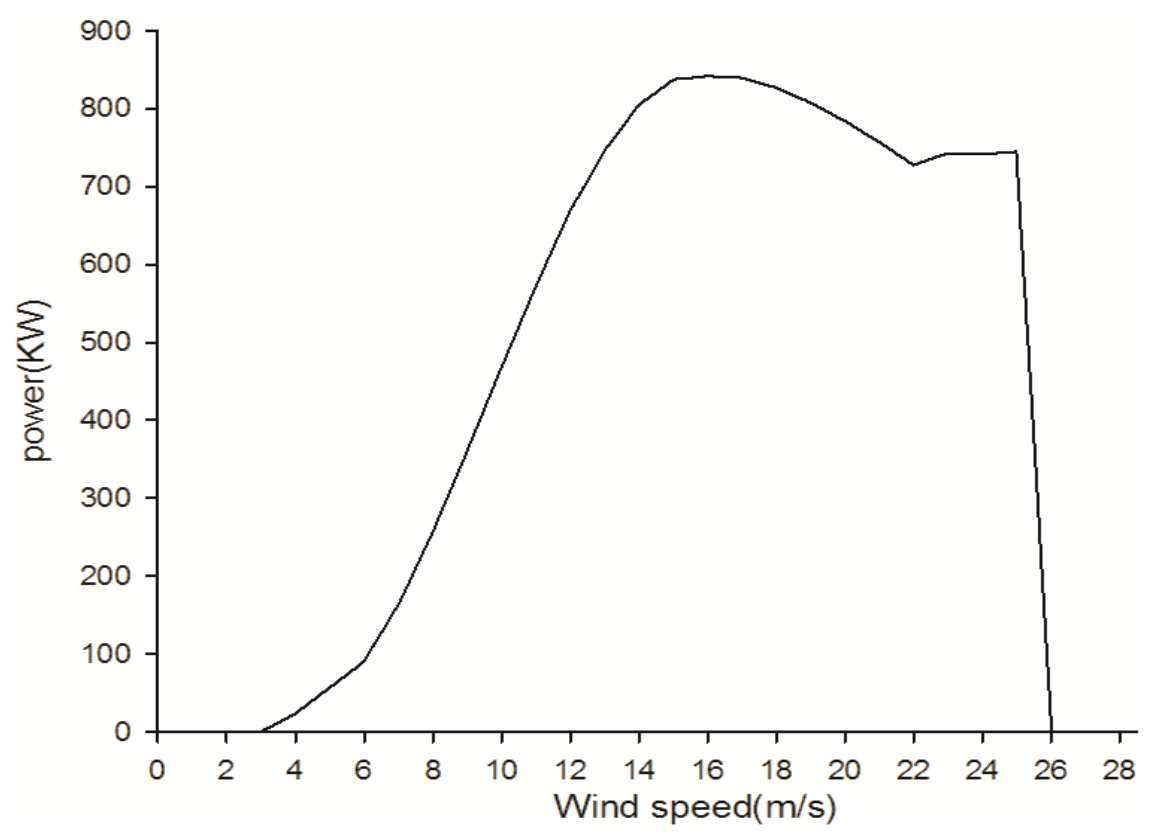

Figure 4. Wind power curve of Nordex N50/800.

The potential effect of dead band should be evaluated. Since wind is caused by differences in atmospheric pressure, it is widely accepted that there is inherent temporal continuity in the wind speed [6]. Therefore, it is reasonable to speculate that once the wind speed fluctuates around the startup speed, the likelihood that a wind turbine to shut down in the following time span is high. The intervals between consecutive startup/shutdown are calculated and their cumulative distribution functions are plotted as shown in Table 3.

The horizontal plot denotes interval between consecutive startup/shutdown events. The vertical plot denotes the likelihood of shutdown of wind turbine within a given time span. It can be observed from Table 3 that once a Nordex N50/800 turbine startup, the likelihood that it will be shutdown again within 10 minutes is around $25 \%$ and the likelihood that it will be shutdown again within 40 minutes is over $50 \%$. It seems that startup speed with dead band is promising to avoid unnecessary startup/shutdown operation of wind turbines.

\section{Numerical Simulation}

Appropriate configuration of dead band plays a key role to the reduction of number of startup. Startup speed of Nordex N50/800, $3.0 \mathrm{~m} / \mathrm{s}$, is used as lower boundary of dead band. $3.1 \mathrm{~m} / \mathrm{s}, 3.2 \mathrm{~m} / \mathrm{s}$ to $5.0 \mathrm{~m} / \mathrm{s}$ with a step of $0.1 \mathrm{~m} / \mathrm{s}$ are used as upper boundary of the dead band.

\subsection{Reduction in the Number of Startup}

The number of startup, as well as number of consecutive startup within $10 \mathrm{mi}-$ nutes associate with various upper boundaries are calculated and plotted as shown in Figure 5.

- The number of startup declines notably and unambiguously with higher up- 
per boundary adopted. The original number is 31,213 (about 1419 times a year) while it becomes 19,518 (about 887 times a year) with an upper boundary of $3.5 \mathrm{~m} / \mathrm{s}$. The number of startup reduced by half to 14,201 (about 646 times a year) with an upper boundary of $4.0 \mathrm{~m} / \mathrm{s}$.

- The decline ratio falls off with higher upper boundary adopted. The decline ratio with an upper boundary above $3.5 \mathrm{~m} / \mathrm{s}$ is notably milder as compared to those below $3.5 \mathrm{~m} / \mathrm{s}$.

- The number of startup/shutdown within 10 minutes declines even faster than the number of startup. The original number is 7750 (about 352 times per year) while it becomes 1414 (about 64 times per year) with an upper boundary of $3.5 \mathrm{~m} / \mathrm{s}$, about $18 \%$ of the original number. The decline ratio above $3.5 \mathrm{~m} / \mathrm{s}$ drops notably. The number of startup/shutdown within 10 minutes reduced to 352 (16 times per year) with an upper boundary of $4.0 \mathrm{~m} / \mathrm{s}$.

A wind turbine without dead band could perform startup 30 times a day due to fluctuation in wind speed. The number decreases to 13 and 11 when dead band of $3.5 \mathrm{~m} / \mathrm{s}$ and $4.0 \mathrm{~m} / \mathrm{s}$ are utilized.

\subsection{Reduction in the Wind Power Generation}

The number of startup is reduced at the cost of reduction in wind power generation. The reduction in potential electricity generation associate with various upper

Table 3. Likelihood of re-shutdown within given time.

\begin{tabular}{cccccc}
\hline Interval (min) & Likelihood & Interval (min) & Likelihood & Interval (min) & Likelihood \\
\hline 10 & $24.82 \%$ & 70 & $62.99 \%$ & 130 & $73.23 \%$ \\
20 & $38.08 \%$ & 80 & $65.30 \%$ & 140 & $74.32 \%$ \\
30 & $46.25 \%$ & 90 & $67.37 \%$ & 150 & $75.27 \%$ \\
40 & $52.19 \%$ & 100 & $69.17 \%$ & 160 & $76.19 \%$ \\
50 & $56.64 \%$ & 110 & $70.67 \%$ & 170 & $77.01 \%$ \\
60 & $60.11 \%$ & 120 & $72.06 \%$ & 180 & $77.73 \%$ \\
\hline
\end{tabular}

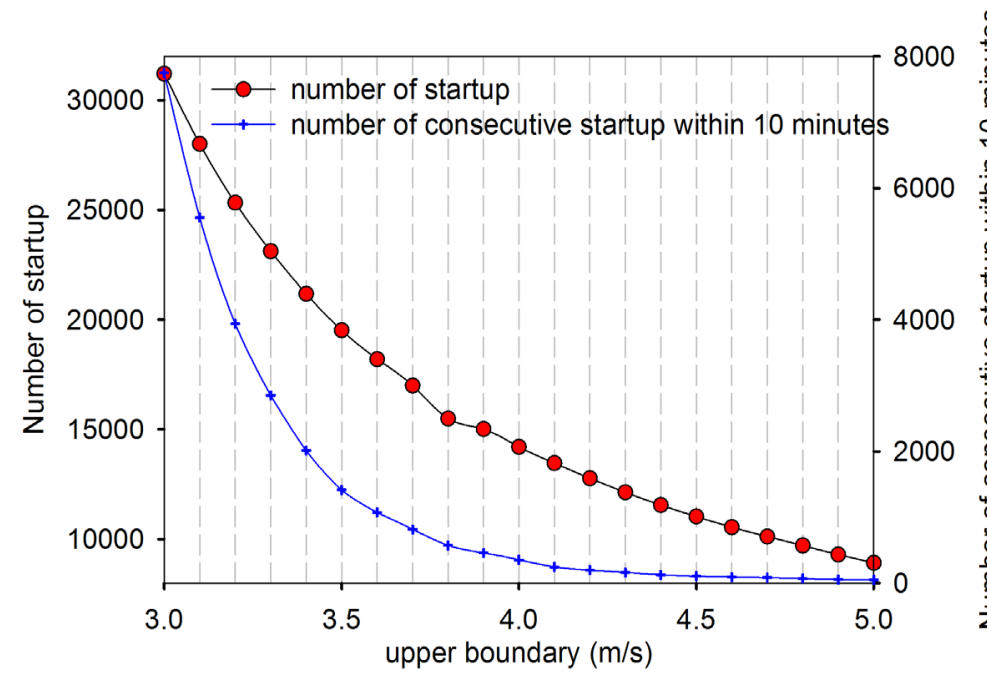

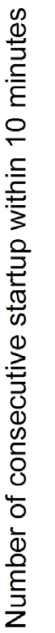

Figure 5. CDF of intervals between consecutive shutdowns. 
boundaries are calculated and plotted as shown in Figure 6 .

- Since wind power is proportional to the cube of wind speed, a narrow dead band will only result in trivial reduction in wind power generation.

- It can be observed that escalation ratio of reduction in wind power generation do not change abruptly. The loss in wind power generation escalated to $506,777 \mathrm{kWh}$ throughout all 22 years $(23,035 \mathrm{kWh}$ per year), which is about 3.5 times higher than that of $4.0 \mathrm{~m} / \mathrm{s}$.

\subsection{Selection of the Upper Boundary of Dead Band}

Since reduction in the number of startup is achieved at the cost of reduction in wind power generation, selection of the boundary of dead band should be determined based on tradeoff between the potential benefit and the cost. The cost induced by reduction in wind power production could be roughly evaluated with historical wind data. The benefit due the reduction in startup should be evaluated with enhanced reliability and availability. Since reliability and availability of wind turbines are determined by a series factors, it is not feasible to quantify the benefit due to the reduction in startup/shutdown of wind turbines. Therefore, it is acceptable to select an affordable cost as the boundary of dead band for the potential benefit of uncertainty.

The N50-800 wind turbine in Lamma Island has a capacity factor of about $13 \%$, i.e., annual wind power production is around $911,040 \mathrm{kWh}$. In order to provide an integrated knowledge of the costand benefit of dead band, the loss in wind power generation is divided by the reduction in number of startup/shutdown and listed in Table 4.

- It can be observed from Table 4, Figure 5 and Figure 6 that the annual loss in wind power production are $1919 \mathrm{kWh}, 6236 \mathrm{kWh}, 13,124 \mathrm{kWh}$, and $23,035 \mathrm{kWh}$ with upper boundaries of $3.5 \mathrm{~m} / \mathrm{s}, 4.0 \mathrm{~m} / \mathrm{s}, 4.5 \mathrm{~m} / \mathrm{s}$ and $5.0 \mathrm{~m} / \mathrm{s}$, respectively.

- Since capacitor factor of Lamma wind farm is about 0.13 , its annual wind power production is about $911,040 \mathrm{kWh}$. Percentage of annual reduction to

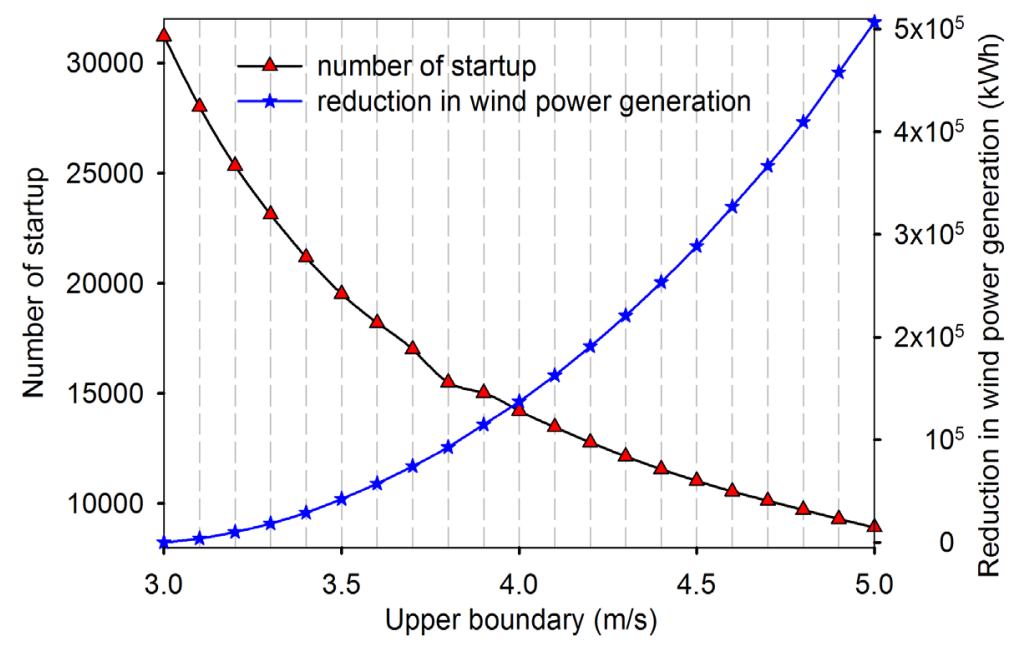

Figure 6. Reduction in power generation associated with various dead bands. 
Table 4. Times of startup with various upper boundaries of deadband.

\begin{tabular}{cccccc}
\hline Upper boundary (m/s) & 3 & 3.5 & 4.0 & 4.5 & 5.0 \\
Time of startup & 31,213 & 19,518 & 14,201 & 11,028 & 8915 \\
Time of startup within 10 minutes & 7750 & 1414 & 352 & 103 & 49 \\
$\begin{array}{c}\text { Loss in power production (kWh) } \\
\text { Annual reduction in power } \\
\text { production (kWh) }\end{array}$ & 0 & 42,220 & 137,196 & 288,719 & 506,777 \\
$\begin{array}{c}\text { Percentage of generation reduction } \\
\text { to production }\end{array}$ & 0 & 1919 & 6236 & 13124 & 23035 \\
$\begin{array}{c}\text { Power loss per reduction in startup (kWh) } \\
\text { Power loss per reduction in time of startup } \\
\text { within 10 minutes (kWh) }\end{array}$ & 0 & $0.21 \%$ & $0.68 \%$ & $1.44 \%$ & $2.53 \%$ \\
\hline
\end{tabular}

production is $0.21 \%, 0.68 \%, 1.44 \%$, and $2.53 \%$ with upper boundaries of 3.5 $\mathrm{m} / \mathrm{s}, 4.0 \mathrm{~m} / \mathrm{s}, 4.5 \mathrm{~m} / \mathrm{s}$ and $5.0 \mathrm{~m} / \mathrm{s}$, respectively. The loss in wind power production with upper boundary of $5.0 \mathrm{~m} / \mathrm{s}$ is about 5 times more than that of $4.0 \mathrm{~m} / \mathrm{s}$.

- The reduction in power production associate with dead band of $3.5 \mathrm{~m} / \mathrm{s}$ and $4.0 \mathrm{~m} / \mathrm{s}$ are lower than $1 \%$ of annual production. The power loss per startup and per startup within 10 minutes is $3.6101 \mathrm{kWh}$ and $6.6635 \mathrm{kWh}$, which is notably smaller than $8.0647 \mathrm{kWh}$ and $18.5450 \mathrm{kWh}$ of dead band of $4.0 \mathrm{~m} / \mathrm{s}$. Therefore, $3.5 \mathrm{~m} / \mathrm{s}$ and $4.0 \mathrm{~m} / \mathrm{s}$ are acceptable candidates for upper boundary of dead band.

It is speculated that the number of startup/shutdown within 10 minutes is more important than the number of startup since its impact on reliability and availability of wind turbine is clearer. The number of startup/shutdown within 10 minutes can be reduced from 7750 to 1414 , about $18 \%$ of the original number, with an upper boundary of $3.5 \mathrm{~m} / \mathrm{s}$. Moreover, total number of startup reduced notably from 31,213 to 19,518 by $38 \%$. Therefore, $3.5 \mathrm{~m} / \mathrm{s}$ could be a preferred upper boundary of dead band under HK wind regimes.

The annual reduction in power production under varying wind regimes with various dead bands are calculated and plotted as shown in Figure 7. It can be observed that the reductions in power production concentrate within a narrower band with smaller dead band. The reduction ranges from 1500 to $2254 \mathrm{kWh}$ for a dead band of $3.5 \mathrm{~m} / \mathrm{s}$ and it ranges from 4975 to $7444 \mathrm{kWh}$ for a dead band of $4.0 \mathrm{~m} / \mathrm{s}$. Loss in wind energy production of these years are affordable.

\section{Conclusions \& Discussion}

Startup speed with dead band is proposed in this article to prevent frequent startup/shutdown operation of wind turbines in wind farm with low wind speed.

- Analysis of wind data of 22 years of Cheung Chau meteorological station indicates that there is notable negative correlation coefficient between wind speed and the number of startup. Therefore, the wind farms with low wind 


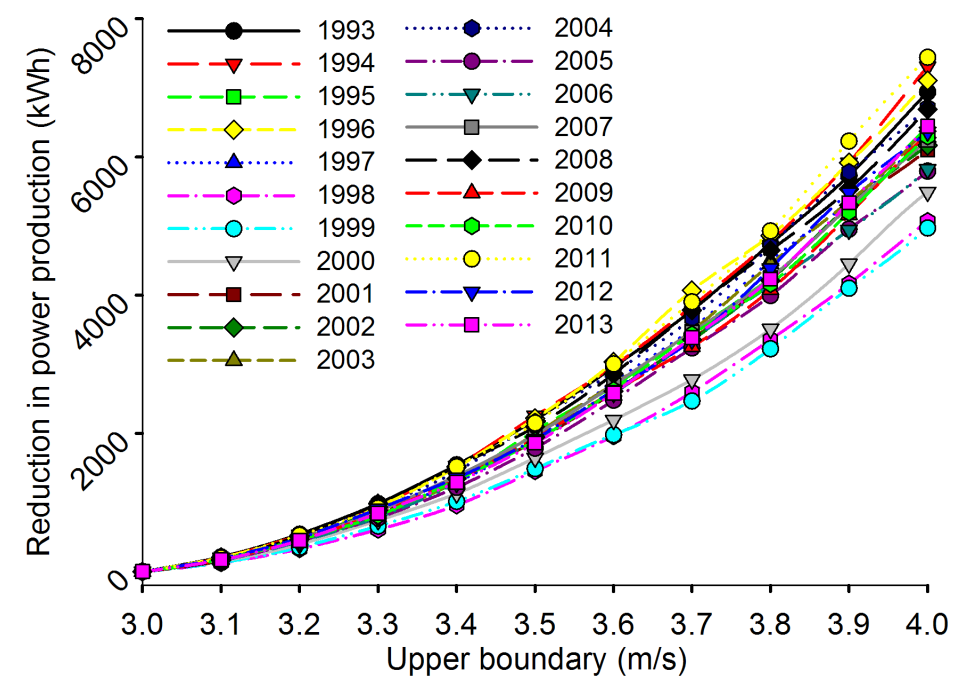

Figure 7. Reduction in wind power production with various dead band boundaries.

speed could undergo much more number of startup and startup/shutdown within 10 minutes, which could negative impact reliability and availability of wind turbines with low and medium wind regime.

- Long term numerical simulation indicates that number of startup and startup/shutdown within 10 minutes could be greatly reduced using startup speed with dead band.

- Comparative simulation suggests that $3.5 \mathrm{~m} / \mathrm{s}$ could be an appropriate upper boundary of dead band. The number of startup could be reduced by $40 \%$ (from 31,213 to 19,518). The number of startup/shutdown within 10-minute could be reduced by $80 \%$ (from 7750 to 1414 ). The reduction in number of startup is achieved at the cost of loss in energy production of $42,220 \mathrm{kWh}$, or $1919 \mathrm{kWh}$ per year.

- Although there are moderate interannual variability in the wind condition, performance of dead band remains stable. Therefore, it is reasonable to determine an appropriate configuration of dead band based on statistical analysis of historical wind data.

It should be pointed out that the data used for numerical simulation is measured at neighboring meteorological station of 10 meters height, which is different from the wind at hub height of Lamma Winds and the potential offshore wind farms. Moreover, there could be notably difference in surface roughness between offshore wind farms and surrounding of investigated Cheung Chau station. Practical and prudent dead band configuration could be determined based on thorough investigation in the onsite hub height wind data.

\section{References}

[1] Walford, C.(2006) Wind Turbine Reliability: Understanding and Minimizing Wind Turbine Operation and Maintenance Costs. Sandia National Laboratories,Rep. SAND-2006-1100.https://doi.org/10.2172/882048

[2] Nielsen, J.J.and Sørensen, J.D.(2011) On Risk-Based Operation and Maintenance of 
Offshore Wind Turbine Components.Reliability Engineering \& System Safety.96, 218-229.https://doi.org/10.1016/j.ress.2010.07.007

[3] GarcíaMárquez, F.P., Tobias, A.M., Pérez, J.P. and Papaelias, M.(2012) Condition Monitoring of Wind Turbines: Techniques and Methods.Renewable Energy, 46, 169-178.

[4] Sangpanich,U., Ault,G. A.,and Lo, K. L.(2009) Economic Feasibility of Wind Farm UsingLow Wind Speed Turbine. Proceedings of 44 th InternationalUniversities Power EngineeringConference, Glasgow, United Kingdom, 1-4, Sept. 2009.

[5] Karuppanan,P. and Mahapatra, K.K.(2014) Active Harmonic Current Compensation to Enhance Power Quality.Journal of Electrical Power \& Energy Systems, 62,144-151.https://doi.org/10.1016/j.ijepes.2014.04.018

[6] Coughran,M.T. (1998) Measuring the Installed Dead Band of Control Valves, ISA Transactions, 37, 147-154.

[7] (2012) Electricity and Heat for 2012.Hong Kong, China. http://www.iea.org/statitics/statisticssearch/report/?country=HONGKONG\&produc $\mathrm{t}=$ electricityandheat\&year $=2012$

[8] Lamma Winds, Pioneering in Hong Kong's Green Power Supply. http://www.hkelectric.com/web/AboutUs/RenewableEnergy/Index_en.htm

[9] Building an offshore wind farm near Lamma Island.

[10] History of the Aeronautical Meteorological Station and Signal Station at Cheung Chau. http://www.hko.gov.hk/wservice/tsheet/pms/his_cch_station_e.htm

[11] Power curve of Vestas.

https://inlportal.inl.gov/portal/server.pt/community/wind_power/424/software

\section{Submit or recommend next manuscript to SCIRP and we will provide best} service for you:

Accepting pre-submission inquiries through Email, Facebook, LinkedIn, Twitter, etc. A wide selection of journals (inclusive of 9 subjects, more than 200 journals) Providing 24-hour high-quality service User-friendly online submission system Fair and swift peer-review system Efficient typesetting and proofreading procedure Display of the result of downloads and visits, as well as the number of cited articles Maximum dissemination of your research work

Submit your manuscript at: http://papersubmission.scirp.org/

Or contact epe@scirp.org 